was heralded by a burst of X-rays and $\gamma$-rays coming from radioactive heavy elements such as nickel - meaning that the heavy material had somehow punched through the lighter layers. "That was the point when theorists realized that $1 \mathrm{D}$ models cannot explain the physics that was observed in the explosion," says Janka.

The rapid increase in available computer power now allows the modellers to run more-ambitious and realistic simulations in a manageable time - currently, Janka needs two to three months to run one supernova in 3D. At some point, researchers say, a digital cataclysm will attain a level of detail adequate to reproduce what occurs in the real Universe. "That is what the big competition is about," says Janka.

\section{Optimistic outlook}

Adam Burrows, an astrophysicist at Princeton University in New Jersey, who is working with Woosley, has already analysed the benefits of 3D models. In 2008, he showed that going to 2D made a simulated supernova of a given luminosity blow up 1.4 times as often as the $1 \mathrm{D}$ version ${ }^{2}$. Repeating the analysis, he found that $3 \mathrm{D}$ models should make supernovae go off twice as easily as in 1D models. The reason, he says, is that $3 \mathrm{D}$ allows the infalling matter to take random walks in all directions - which means that it spends slightly more time interacting with neutrinos and absorbing their energy. Ultimately, the aim is to construct a 3D explosion that is faithful enough to generate a supernova without fail. In the process, the physical forces that govern it should become apparent.

That's why Janka is rushing to fill out the rest of his 3D model to include the neutrino mechanics in the first second of the explosion. He also has to find a computer that can handle the job. He estimates that he needs a computer to perform about $10^{21}$ floating point operations, or flops - roughly 50,000 times the computing power behind his latest simulations. This would mean several months of devoted time from a major supercomputer that can perform a petaflop, or $10^{15}$ operations, per second. With the growth in worldwide computing infrastructure, Quataert says, that is now not a completely outrageous request. "That's part of the reason for optimism that there will be a breakthrough in this problem," he says. Eric Hand

1. Hammer, N. J., Janka, H.-Th. \& Müller, E. Astrophys. J. 714, 1371 (2010).

2. Murphy, J. W. \& Burrows, A. Astrophys. J. 688, 1159 (2008)

\title{
US prepares for climate burden
}

It hasn't always been easy to get the White House to lead on climate change, so for years the question of how to incorporate global warming into long-range planning and public infrastructure in the United States has fallen to cities, states and individual federal agencies. Now, the Obama administration is looking to fold these independent efforts into a comprehensive adaptation strategy for the entire country.

Last week, about 150 experts gathered in Washington DC to swap ideas and information about exisiting adpatation plans across the country and to consider how the federal government should coordinate and encourage further steps. Ordered last year by John Holdren, Obama's chief science adviser, the three-day National Climate Adaptation Summit served as a brainstorming session where users and providers of 'climate services' could talk about their needs and capabilities. The gathering took place just a week after the National Research Council called on the government to develop a national strategy for dealing with the impacts of a changing climate.

"There's a sense that this is a moment to put everything together and figure out what we are going to do to prepare," says Richard Moss, a senior scientist at the Joint Global Change Research Institute in College Park, Maryland, and former director of the US Global Change Research Program. "And I give the administration credit for holding this meeting and asking for ideas, rather than just rolling out an answer."

Increased drought, heatwaves, forest fires, severe storms and rising sea levels in coastal cities are among the challenges that climate change could pose for the United States. A National Climate Service, modelled on the National Weather Service at the National Oceanic and Atmospheric Administration (NOAA) in Silver Spring, Maryland, could help local authorities to anticipate such stresses and provide a onestop clearinghouse for information designed to reduce susceptibility to climate-related disasters. While seeking congressional approval for the service, NOAA is pushing forwards with a reorganization that would essentially make the approach a reality. The plan includes a series of regional climate centres to help provide guidance for local governments and businesses.

The goal, says Thomas Karl, interim director of NOAA's Climatic Service, is to provide useful information about environmental impacts so that planners can assess water supplies, update flood-plain maps or decide how high to build levies. But the first step, he says, is to establish "good communication with those who will want to use the data”.

To be effective, the centres will need to be adept at translating hard data into metrics and standards to guide public and private infrastucture projects, says Anne Choate, vice-president of the business consultancy ICF International. "There's this gap between what the engineers say they need and what climate scientists can provide," she says.

Some scientists have already begun closing that gap. In 2008, a team led by Don Wuebbles, an atmospheric scientists at the University of Illinois at Urbana-Champaign, analysed global climate models to produce more detailed climate projections for the city of Chicago. The results suggest that the city could be significantly warmer in 2100 , with implications for everything from power generation to the kinds of tree that the city is planting today.

"We're going to look more like New Orleans than Chicago," says Joyce Coffee, who handles the city's adaptation planning. "We need to be planting species that will survive current cold snaps and thrive in a much warmer climate in the future."

Other federal initiatives are focusing on environmental planning at the regional level. For instance, the Interior Department is setting up 'Landscape Conservation Cooperatives' to bring federal agencies together with state and local governments to collaborate on planning for issues ranging from wildfires and water supplies to invasive species and energy development. "I think this is going to be the new model for environmental adaptation strategies," says Deputy Interior Secretary David Hayes.

An adaptation task force formed by the White House last year will incorporate the results of the summit into a white paper scheduled for release this autumn. Jeff Tollefson 